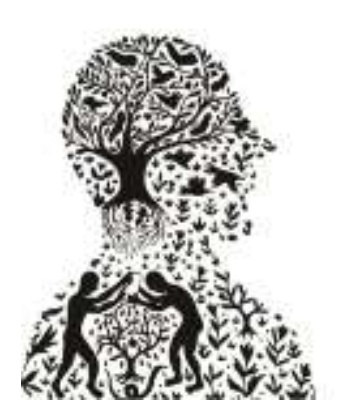

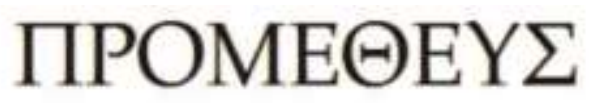 \\ Journal of Philosophy \\ n. 33 maio - agosto de 2020 \\ Dossiê Linguagem e Cognição \\ Editores: Marcus Souza, Marcos Silva \& Maxwell Lima Filho
}

\title{
COMO SER INTENCIONALISTA E DISPOSICIONALISTA
}

\author{
André Leclerc \\ $\mathrm{UnB} / \mathrm{CNPq}^{1}$
}

\begin{abstract}
RESUMO: Intencionalistas acreditam que a intencionalidade, a propriedade relacional de ser acerca de algo, é constitutiva do mental. De acordo com a Tese de Brentano: 1) o mental é intencional; 2) nada físico é intencional. O disposicionalismo, acredito, deve ser ampliado para incluir todas as propriedades mentais que também são propriedades disposicionais realizadas fisicamente no cérebro e no sistema nervoso como um todo, da mesma maneira que a solubilidade do açúcar é realizada na sua estrutura molecular. Meu objetivo é mostrar como podemos ser intencionalistas (aceitar a primeira parte da Tese de Brentano) e disposicionalistas ao mesmo tempo (aceitar que os estados, atos e eventos mentais intencionais tenham uma base física de realização). Resumindo em um slogan: o intencional é a manifestação de disposições mentais. As disposições em geral, e as disposições psicológicas em particular, têm dois lados (two-sidedness): elas pressupõem uma realização física, de um lado, e de outro, uma manifestação que é propriamente mental. Uma exposição sobre a linguagem se faz necessária neste contexto, pois as representações públicas também instanciam propriedades semânticas que são intencionais, e muitos de nossos estados mentais têm conteúdo especificado pelo uso de uma frase de uma língua pública.
\end{abstract}

PALAVRAS-CHAVE: Intencionalismo. Disposicionalismo. Mental. Físico. Manifestações.

ABSTRACT: Intentionalists believe that intentionality, the relational property of being about something, is constitutive of mentality. Brentano's thesis says: 1) the mental is intentional; 2) nothing physical exhibits that property. Dispositionalism, I believe, should be extended to include all mental properties, which are also dispositional and realized physically in the brain, like the solubility of sugar which is realized in its molecular structure. My aim is to show how we can be intentionalists (by accepting the first part of Brentano's Thesis) and dispositionalists at the same time (by accepting that mental states, acts and events have a physical base of realization). In a nutshell: the intentional is the manifestation of mental dispositions. Dispositions in general, psychological dispositions in particular, are two-sided and presupposes, on the one hand, a physical realization, and a manifestation which is properly mental, on the other. Something has to be said about language in that context, because public representations instantiate semantic properties which also are intentional, and many of our mental states have their content specified by the use of a sentence belonging to a public language.

KEYWORDS: Intentionalism. Dispositionalism. Mental. Physical. Manifestations.

\footnotetext{
${ }^{1}$ Essa pesquisa foi desenvolvida graças a uma bolsa de produtividade do CNPq (processo 305365/20126). Quero agradecer a Dra. Gesuína de Fátima Elias Leclerc pela leitura sempre atenta e as observações valiosas.
} 
Algo extraordinário apareceu cedo na evolução da vida - ou talvez junto com ela -, quando organismos adquiriram a capacidade de representar, de alguma forma, o meio ambiente e de antecipar acontecimentos. Não sabemos com precisão quando e por quê. Certamente, para ter a capacidade de representar, um organismo deve apresentar um certo nível de complexidade. São chamados hoje de "intencionalistas" aqueles que acreditam que esta propriedade relacional, a de ser acerca de algo, é constitutiva do que é, para um organismo, ter uma mente. O que é mental é intencional. Essa propriedade relacional pode ser instanciada não só por representações mentais de todo tipo, como estados (crenças, desejos, intenções), eventos (como percepções, sensações, dores, orgasmos, etc.), e atos mentais (julgar, decidir, lembrar, deliberar), como também por representações públicas como fotografias, retratos, partituras, gráficos, mapas, frases, palavras, etc. Temos boas razões para pensar que representações públicas existem e são úteis somente porque existem organismos providos de mentalidade que as usam na realização de seus planos, em particular nos planos comunicacionais. As representações públicas são artefatos concretos cuja definição remete a necessidades, desejos, ou intenções de usuários potenciais. De outro modo, nenhuma representação pública (palavras, gráficos, mapas, etc.) poderia referir a algo ou ter um referente. Todas as representações mentais e públicas "referem" ou "indicam", ou ainda "apontam" para algo que pode ser um objeto material concreto, algo abstrato (o único número primo par), um estado de coisas simplesmente possível (que Rio Grande do Sul seja um Estado independente da federação brasileira), um fato (a Inglaterra está fora da UE), um evento (está chovendo), um outro estado mental (minha alegria motiva meu desejo de ligar para minha esposa), uma propriedade instanciada (viajar a 800 quilômetros por hora), uma propriedade nunca instanciada (viajar mais rápido do que a luz), algo inexistente (o Eldorado), ou ainda um artefato abstrato que necessita de uma base material, como é o caso das instituições e dos personagens fictícios, que não existem sem uma base material para funcionar, mas não se identificam com ela (o STF não se identifica com um edifício nem com grupo de juízes, e os personagens fíctícios, como Hamlet ou Sherlock Holmes, são objetos culturais que existem graças a livros concretos (token books), películas, CDs, e a atividade mental de pessoas interessadas, etc.). Vivemos cercados de artefatos e as representações públicas são claramente artefatos. Temos até boas razões para acreditar que muitas de nossas representações 
mentais também são artefatos, quando o conteúdo mental é conceitual e depende da existência de convenções linguísticas e de regularidades sociais.

Como um organismo pode produzir e manter estados mentais que são acerca de outra coisa? Trata-se de um problema que Brentano teve que enfrentar. A resposta que quero oferecer a esse problema é simples e naturalista: o mental é intencional e o que é mental é disposicional. Noutras palavras, o que é mental é a manifestação de disposições, e como disposições precisam de uma base de realização física, o mental é assim naturalmente amarrado ao físico.

As propriedades intencionais das representações (mentais ou públicas) são aquelas que determinam os objetos dos atos (estados ou eventos) mentais e também das representações públicas. No caso dessas últimas falamos de propriedades semânticas, como ter um sentido ou ter uma referência. Essas propriedades relacionais $\mathrm{e}$ extrínsecas não são determinadas pelas propriedades intrínsecas das representações físicas. As ocorrências concretas da palavra "lua", consideradas materialmente, têm propriedades físicas e químicas intrínsecas, mas elas não determinam as condições de aplicação do termo (seu sentido) nem sua referência. Pensar de outro modo nos traria de volta para uma concepção mágica da linguagem. As propriedades físicas ou químicas dos exemplares concretos de uma palavra, bem como a forma e tamanho das letras (ou altura do som), não determinam a maneira como ela é usada; as moléculas que compõem a tinta de um exemplar concreto da palavra "lua" têm propriedades físicas e químicas intrínsecas, mas nenhuma dessas propriedades determinam qual o sentido ou a referência de "lua"2.

Ninguém decide sozinho acerca do significado de uma palavra (com a exceção das definições estipulativas e neologismos). Tive que aprender o significado de "lua" em português, de "lune" em francês, etc. São regularidades sociais admitidas numa comunidade que determinam as propriedades semânticas das palavras usadas; por exemplo, "lua" designa em português o único satélite natural da Terra; isso se deve ao fato de que os falantes do português, durante gerações, usaram essa palavra para se referir àquele objeto. Depois de Galileu, a palavra ganhou um significado a mais; ela passou a designar também qualquer satélite natural de qualquer planeta (e.g. as luas de

\footnotetext{
${ }^{2}$ Sobre isso, ver Robert Stalnaker (1989 e 1990).
} 
Júpiter). Palavras ou signos não têm o mesmo significado para sempre ou em todos os contextos de uso. Um aperto de mão entre dois desconhecidos pode ser um sinal de boa vontade e colaboração entre duas pessoas; entre duas pessoas que acabam de brigar, tem outro significado; entre dois inimigos de longa data, é ainda diferente; quando envolve dois velhos amigos, pode ser o sinal de que a relação esfriou (por que eles não se abraçam?); e o famoso aperto de mão do Marechal Pétain e de Adolf Hitler causou uma profunda tristeza, porque significou, para grande parte da nação francesa, a rendição. Esse fenômeno da variabilidade do sentido das palavras usadas em contexto, nós o chamamos de plasticidade do sentido. A plasticidade não se explica em termos de ambiguidade. Temos um caso autêntico de ambiguidade quando a lista dos possíveis significados associados a uma palavra é finita, fechada. A inspiração aqui vem da ideia de textura aberta introduzida por Friedrich Waismann (1945): há sempre novas possibilidades de aplicação para termos já em uso. Nunca podemos fechar a lista.

Línguas são regularmente apresentadas de maneira muito abstrata, como sistemas recursivos que permitem a formação de um número potencialmente infinito de frases bem formadas (ou de pares som-sentido), transmitidos de geração em geração. Mas, são seus usuários que mantêm a língua viva a cada geração. Cada falante deve aprender a língua, mas ninguém consegue "absorver" a língua por inteiro (gramáticos e lexicógrafos, talvez, sejam aqueles que mais se aproximam desse ideal). Assim, há muitas diferenças entre qualquer par de falantes do português quanto ao conhecimento da língua: esse conhecimento é desigual, de um falante para outro. O mesmo vale para o repertório de conceitos que cada um possui. O conhecimento, por mais incompleto que seja, que um falante adquire de uma língua é o que chamamos de idioleto. E o que chamamos de "português" é uma abstração sobre os idioletos dos falantes do português. Os lexicógrafos tentam estabelecer quais são as convenções linguísticas, a partir das falas de indivíduos dentro de uma comunidade de falantes, e as convenções linguísticas são regularidades sociais valendo dentro de uma comunidade de falantes. Um locutor é considerado competente quando sabe usar as palavras com sucesso na maior parte das ocasiões de uso. A capacidade de usar corretamente palavras deve ser realizada fisicamente de alguma maneira no cérebro, normalmente pela repetição e pelo treinamento, que tem por efeito a criação de pistas neuronais (neural pathways) que 
facilitam futuras execuções com o caráter de automatismos. Grandes performances na dança, na música, nos esportes, dependem disso. É a melhor hipótese que temos. Há diferenças entre os idioletos dos falantes da mesma comunidade, é óbvio. Nunca usamos todo o repertório linguístico de uma só vez, mas, nossa capacidade de usar as partes não usadas não é perdida quando não é exercitada. Basta as circunstâncias serem favoráveis para ativar essa capacidade. Aprendemos a usar a linguagem com o treino e a repetição, e nossa capacidade de usar a linguagem pode melhorar com o tempo, com o treino, o ensino, estudo e o exemplo. Finalmente, essa capacidade de usar a linguagem (ou partes dela) nos segue, não importa onde estivermos, como nosso repertório de conceitos e nossas atitudes proposicionais. Qual a melhor explicação desses fatos comuns? A resposta em uma só palavra é: disposições!

As disposições têm uma base física de realização. A solubilidade do açúcar é realizada na estrutura molecular do açúcar; a fragilidade do vidro, na sua estrutura molecular, e assim por diante. O mesmo vale para disposições psicológicas como nossas capacidades fundamentais (como reconhecer os rostos), nossas atitudes (crenças, desejos, etc.), nossas habilidades ou capacidades adquiridas, nossas competências (saber dirigir um carro, falar uma língua, tocar um instrumento, dominar uma técnica, dominar uma bateria de conceitos, etc.). Nosso vocabulário disposicional é simplesmente imenso, como Ryle revelou na sua grande obra, The Concept of Mind (1949).

Desde a década de 1990, as disposições voltaram a ocupar o palco em filosofia da ciência e da mente. A novidade veio da Austrália, onde filósofos como D. M. Armstrong, U. T. Place e George Molnar defendem uma interpretação realista das propriedades disposicionais, o que contrasta com a posição tradicional dos empiristas. $\mathrm{O}$ behaviorismo tradicional, de inspiração empirista, recorre às disposições com certa relutância e somente na medida em que exista uma tradução para frases condicionais que eliminem a referência a qualquer episódio "privado". Propriedades disposicionais físicas, como a solubilidade, a condutividade, a resistência, etc., bem como propriedades disposicionais psicológicas, como as habilidades, hábitos, inclinações, tendências, gostos, competências, etc., não podem ser observadas. Muitos filósofos, nessa tradição, “eliminam" as disposições através de uma "análise condicional". Elas são aceitáveis na medida em que podemos eliminá-las sem perda de sentido num programa de tradução (e.g. o programa de tradução de Ryle e as "frases de redução" de Carnap). Na metafísica analítica, desenvolvida sobretudo nas últimas décadas, a concepção de disposição defendida por George Molnar (2003), U. T. Place, C. B. Martin, D. M. Armstrong ( $c f$. 
Crane 1996) e outros, é realista. O mesmo vale para a concepção de Stephen Mumford \& Rani Anjum (2011). As disposições deixaram de ser metafisicamente e epistemicamente suspeitas. Desapareceu, aos poucos, a tentação de reduzir ou de eliminar as propriedades disposicionais na metafísica, na filosofia da mente e na filosofia da ciência.

A atribuição de uma disposição pressupõe a verdade de um condicional contrafactual (subjuntivo). Jansen (2007), um especialista em Aristóteles, sugere a seguinte forma lógica para as propriedades disposicionais: (dyn (MC)) (x), em que "dyn" está para lembrar a dynamis aristotélica, "M" para as manifestações da disposição, "C" para o conjunto de circunstâncias favoráveis ou auspiciosas, e " $\mathrm{x}$ " para qualquer objeto podendo instanciar a propriedade. A análise das propriedades disposicionais que adotamos neste ensaio foi proposta recentemente por Justin C. Fisher. Se um pedaço de açúcar tem a propriedade disposicional de solubilidade, então é verdade que se ele fosse colocado numa solução aquosa, então se dissolveria. Se a água de uma garrafa fosse envenenada, então, se ela fosse ingerida, ela causaria danos à saúde. Estes são condicionais contrafactuais (ou contrafáticos), ou condicionais subjuntivos. O verbo principal do antecedente está no modo verbal subjuntivo e o verbo principal do consequente está no modo condicional. De modo geral o conceito de disposição que vamos pressupor e usar aqui pode ser enunciado assim:

Uma coisa $\mathrm{X}$ está disposta a dar uma resposta do tipo $\mathrm{R}$ a um estímulo do tipo E em circunstâncias do tipo C, se e somente se, se $\mathrm{X}$ ou qualquer réplica molecular de $\mathrm{X}$ fosse exposta a um estímulo do tipo $\mathrm{E}$ em circunstâncias do tipo $\mathrm{C}$, então $\mathrm{X}$ manifestaria uma resposta do tipo $\mathrm{R}^{3}$.

Nossa capacidade de usar corretamente uma palavra depende de sua associação a um conjunto de disposições. Certas disposições, quando ativadas, permitem o reconhecimento da palavra (ou de certo padrão sonoro ou gráfico); outras ativam processos motores na hora dos proferimentos e outras ainda determinam as condições de aplicação da palavra, seu sentido. Assim, cada palavra é associada a um feixe de disposições. Isso não parece óbvio para quem reflete sobre sua língua materna. Condillac dizia que comunicamos sem saber antes de saber comunicar. O aprendizado

\footnotetext{
${ }^{3}$ Ver Justin C. Fisher, 2013, p. 450.
} 
da primeira língua não resulta de nenhum treinamento especial. Tudo parece tão natural, um simples jogo de imitação sem esforço, até o aprendizado da escrita na escola, com a gramática e tudo mais, que representa um primeiro verdadeiro treinamento especial com a linguagem. Ao chegar na escola, no entanto, já sabemos falar. Mas quando se trata de línguas adicionais, precisamos treinar a pronúncia, aprender a reconhecer as palavras e a segmentar corretamente a cadeia falada e, ainda, a procurar várias vezes a mesma palavra no dicionário para fixar seu significado.

John L. Austin introduziu uma distinção muito importante na teoria da linguagem, a distinção entre as convenções descritivas e as convenções demonstrativas. As convenções descritivas são capturadas pelos lexicógrafos. Depois de muitas observações e consultas, o lexicógrafo chega à conclusão de que a palavra "café" designa algo como a semente de um arbusto tropical que, uma vez torrada e moída, produz uma bebida estimulante e levemente amarga com o acréscimo de água quente. Essa descrição é o núcleo de sentido da palavra, mas a palavra tem outros usos ligados ou derivados desse núcleo de sentido. "Café" às vezes pode designar uma cor, ou uma certa quantidade da bebida (um café = uma xícara de café), ou ainda o lugar onde se pode beber café etc. A convenção descritiva é uma abstração sobre os usos permitidos numa comunidade. Sempre tem um caráter geral, pois nunca remete a algo particular, real, histórico, concreto.

Agora, como falamos sempre em contextos altamente específicos, o uso da palavra "café" normalmente tem um significado muito claro determinado pelas convenções demonstrativas. Essas convenções são um conjunto de indicações que fixam com precisão o significado em contexto. A frase “Querida, o café está pronto!” dita às 7 horas da manhã significa o mesmo que: "Vem, a cafeteira está na mesa"; por sua vez, “Querida, quer um café?” significa: “Gostaria de uma xícara de café?”. A frase "Querida, me desculpe, esqueci de comprar o café" significa que não comprei o pó de café, etc. Essas frases são compreendidas imediatamente, sem dificuldade, em razão de um conjunto de indicações contextuais claras que elimina qualquer equívoco. Elas determinam condições de verdade ou de satisfação facilmente acessíveis para todos os participantes da conversação, e os termos usados remetem a objetos, eventos ou situações concretas.

O que é parte de meu idioleto é o núcleo de sentido das palavras, não o sentido enriquecido e determinado em contexto pelas convenções demonstrativas. O sentido da palavra "cortar", por exemplo, pode variar muito de um contexto para outro. O que 
podemos dizer sobre as disposições de uma pessoa competente que sabe usar a palavra “cortar", uma palavra suscetível a enormes variações contextuais de sentido? Cortamos diversas coisas ou materiais com diversos instrumentos (faca, machado, serra, bisturi, laser, cortador de grama, fio quente, canivete, espada, punhal etc.). Podemos afirmar o seguinte: se ela tivesse considerado a questão de saber se o uso da palavra "cortar" em circunstâncias favoráveis é apropriado ou não, então, após considerar seu melhor juízo, ele responderia sinceramente que sim. Wittgenstein recomenda associar a compreensão de uma expressão, frase ou série aritmética a uma habilidade (o "domínio de uma técnica") e não a algo que teríamos em mente, um conceito, uma ideia, uma imagem, uma função ou fórmula que teria o poder de determinar de uma só vez todas as aplicações possíveis de uma expressão linguística ou de uma regra e que seria presente de alguma forma em todas as aplicações corretas. Essa orientação de Wittgenstein é muito bem-vinda para as línguas naturais. Querer aplicar às línguas naturais as mesmas técnicas de análise do discurso usadas para as linguagens arregimentadas da lógica e das ciências não dá bons resultados. Em muitos casos não sabemos exatamente qual é a função que devemos associar a uma expressão como seu significado. Uma maneira de mostrar isso de modo convincente é usar a notação - - - $\lambda$ para especificar o significado de uma palavra muito comum de uma língua natural sujeita a enormes variações contextuais, como a palavra "cortar". Cortar a grama é uma atividade muito diferente de cortar um bolo, ou cortar com um bisturi, com um machado etc. O resultado é a seguinte função:

$\lambda \mathrm{X} \lambda \mathrm{x} \lambda \mathrm{y}[\mathrm{X}(\mathrm{y}) \&($ cortar à maneira de $\mathrm{X})(\mathrm{x}, \mathrm{y})]$

em que "X" é uma variável de segunda ordem que percorre o domínio das "maneiras de cortar", " $x$ " está para o agente do contexto, e "y" para qualquer objeto a ser cortado (ver Recanati, 2010, p. 34). Trata-se de algo (uma função) extremamente abstrato, portanto, e a ideia de que algo dessa natureza deve estar presente na mente de qualquer falante competente, em todas as ocasiões de uso correto da palavra "cortar" é, simplesmente, delirante. E nem consideramos os usos figurados da palavra, como "cortar o orçamento", "cortar a luz" etc. Mas podemos sempre atribuir uma disposição (ou feixe de disposições interligadas) a um locutor competente capaz de usar a palavra “cortar”. Sua compreensão da expressão “cortar”, ou de qualquer outra expressão, frase ou série aritmética, depende de uma habilidade. 
Uma "semântica vetorial" pode ajudar a entender como nossa compreensão se ajusta e modifica o núcleo de sentido associado a uma palavra em função de fatores contextuais. Aprendemos a usar a palavra "cortar" em relação a diversas práticas, em várias situações onde se usa diferentes instrumentos. Nosso conhecimento enciclopédico do mundo, das regularidades naturais e sociais, é aqui de importância decisiva. O núcleo de sentido para "cortar" poderia ser algo como: "separar ou dividir por meio de um corte". Mas cortar um bolo com uma faca e cortar uma árvore com um machado etc., são práticas totalmente diferentes. $O$ uso que fazemos da palavra "cortar" se ajusta às circunstâncias, às atividades realizadas. No espaço vetorial que segue, na Figura 1, o comprimento das setas horizontais representa a frequência com a qual um instrumento cortante é usado (ou a probabilidade segundo a qual a palavra é usada) considerando a minha experiência pessoal. $\mathrm{Na}$ imensa maioria dos casos, quando corto algo, ou quando ouço alguém falar em cortar algo, é com uma faca. A representação para o mesmo núcleo de sentido no idioleto de um lenhador ou de um cirurgião resultaria em algo bem diferente. A seta vertical poderia ser prolongada indefinidamente, permitindo a introdução de novos instrumentos cortantes (canivete com raio laser, robô cortador de grama etc.). Como já foi dito, textura aberta não é e não se explica em termos de ambiguidade.

"Separar ou dividir por meio de um corte"

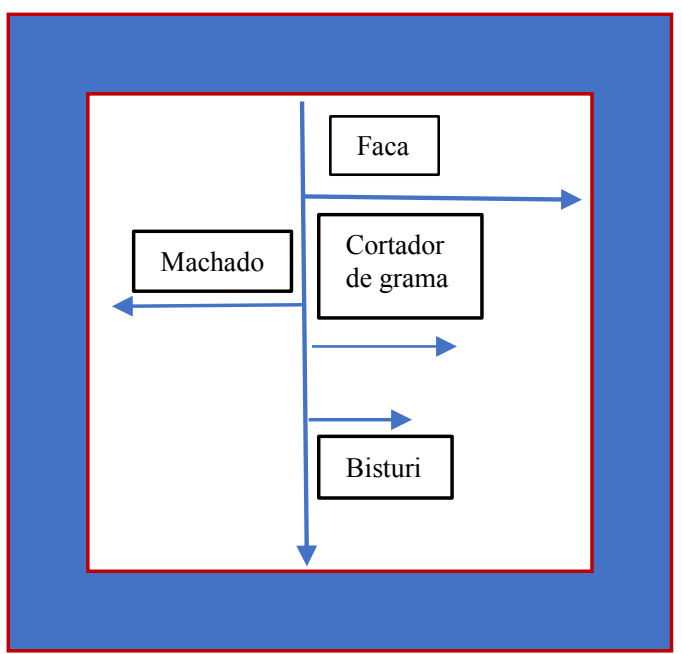

Figura 1 (elaborada pelo autor)

(No meu idioleto, o espaço vetorial para a palavra "cortar" poderia ser representado assim) 
Minha hipótese de trabalho neste breve ensaio poderia ser descrita assim: as disposições psicológicas, como as outras disposições (físicas), têm duas faces ${ }^{4}$ : uma, objetiva, como realização física no cérebro dos agentes, e outra, subjetiva e, propriamente, psicológica, como manifestação intencional. Conceitos, que são disposições, podem ser analisados em termos funcionais (como Frege viu muito bem) e que se manifestam nas suas aplicações. Os conhecimentos em geral são disposições; mais especificamente, o conhecimento dos significados (a competência semântica) é um conjunto enorme de disposições. A consciência também é uma capacidade. Sigo Lynne Rudder Baker quando disse que "[u]ma pessoa é um ser consciente mesmo quando dorme e deixa de manifestar consciência". . A famosa "perspectiva em primeira pessoa" é a manifestação de uma disposição. Na mesma veia, Simone Gozzano reconstrói as propriedades fenomenais (qualia) como a manifestação de propriedades disposicionais ${ }^{6}$.

As disposições não funcionam em isolamento. Peter Geach dá o exemplo de um aquecedor que tem a capacidade de aquecer e manter a temperatura de uma sala em até, digamos, $28^{\circ} \mathrm{C}$, sob a condição de que as janelas estejam todas fechadas. Um dançarino experiente tem muito mais facilidade para aprender uma nova dança do que um principiante, porque pode usar movimentos que já domina perfeitamente e pode coordená-los com um novo ritmo, numa nova sequência. Uma violonista experiente não demora para aprender uma nova melodia; ela já sabe todos os acordes, e combiná-los de uma nova maneira dá pouco trabalho. A noção de repertório é usada em teoria da ação desde Arthur C. Danto (1973). Os repertórios variam muito de uma pessoa para a outra. Algumas podem mexer as orelhas, por exemplo, outras não. A variedade cultural, a diversidade dos interesses, a educação e o trabalho fazem o resto. Cada pessoa acaba tendo um repertório altamente específico, único. Isso se aplica aos idioletos: nossos repertórios de disposições semânticas variam muito de uma pessoa para a outra. Quem fala um segundo ou terceiro idioma, há pouco tempo, tem um idioleto mais pobre do que os falantes nativos; quem estudou mais tempo ou lê muito tem um idioleto mais rico em relação aos amigos com um grau de educação formal inferior ou que lê menos etc.

\footnotetext{
${ }^{4}$ Nancy Cartwright, What Makes a Capacity a Disposition? Center for Philosophy of Natural and Social Sciences. $<$ Http://personal.1se.ac.uk/cartwright/PapersGeneral/what $\% 20 \mathrm{a} \% 20$ capacity $\% 20 \mathrm{a} \% 20$ disposition.pdf> Em particular, p. 4 e 12.

${ }^{5}$ L. Rudder Baker (2013, p. 175).

${ }^{6}$ Ver S. Gozzano (2018).
} 
As atividades se dividem em rotinas e sub-rotinas, elementos de nossos repertórios. Normalmente, a formação de um plano apela exclusivamente para possíveis elementos do repertório do agente. Uma rotina, na maioria dos casos, é algo flexível, e um plano pode ser visto como uma disposição complexa. Conceitos também são disposições, que se manifestam quando identificamos e classificamos objetos, e o repertório de conceitos de um agente cognitivo pode ser muito diferente do repertório de conceitos de outro; mas, em qualquer caso, é nosso repertório de conceitos que alimenta nossa atividade judicativa.

Como já dito, as disposições não funcionam em isolamento. Elas são ativadas em circunstâncias auspiciosas e se manifestam em pacotes. O nível de ativação não é o mesmo para todas as disposições no mesmo pacote. Existe algo como uma hierarquia na ativação das disposições. Uma comparação pode ajudar aqui. Alguém me pede para contar as minhas férias em Pipa. Imediatamente pacotes de informações atravessam a minha mente: a viagem até a praia de Pipa com a família (com vários detalhes associados, nem todos da mesma importância), a chegada no hotel (com detalhes associados), o primeiro banho de mar nas piscinas naturais na praia (com detalhes associados), as refeições no restaurante (com detalhes associados) etc. Com certeza, uma miríade de detalhes é deixada de lado nessa narrativa, por ser julgada irrelevante. Mas são "disponíveis", para mim, e fazem parte do grande pacote de informações sobre minhas férias (a temperatura da água, o tom de voz particular do servidor no restaurante, a limpeza do banheiro de nosso quarto etc., podem ser considerados detalhes irrelevantes).

Isso vale, a fortiori, para as disposições psicológicas. Quando as circunstâncias são auspiciosas e uma disposição é ativada, muitas outras são inevitavelmente ativadas. Temos, para usar um termo que tomo emprestado de Willard van O. Quine, uma espécie de "interanimação" das disposições. Sugiro a seguinte representação para níveis de ativação.

\section{Níveis e força da Ativação}

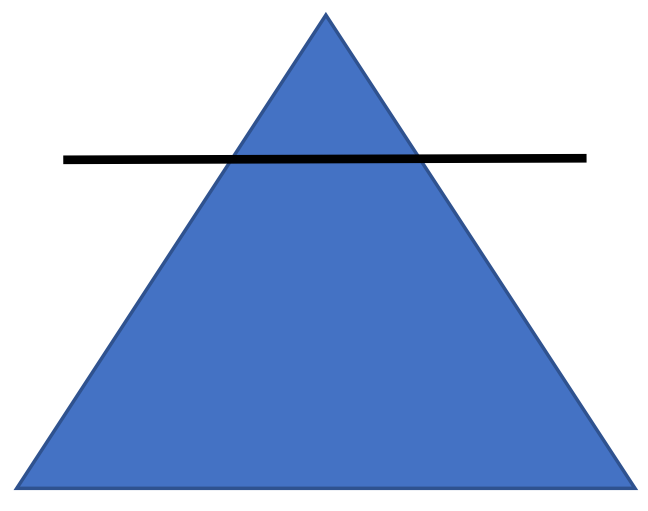


Acima da linha, a ativação é forte e imediatamente relevante para o agente; as manifestações do pacote de disposições são diretamente acessíveis à consciência do agente; abaixo da linha, as outras disposições são cada vez menos relevantes. A ideia é que as disposições psicológicas sempre são ativadas em pacotes, e não isoladamente, e isso se deve ao holismo dos conteúdos mentais, em particular, dos conteúdos conceituais. O que temos aqui é algo que pode lembrar a Rede e o Background de Searle por ter, grosso modo, a mesma função. No topo da pirâmide, acima da barra, temos nossa atividade mental consciente, sempre apoiada na manifestação de nossos repertórios de conceitos, conhecimentos, habilidades, competências, capacidades fundamentais e propriedades fenomenais. Nossas atitudes proposicionais, por exemplo, são individuadas pelo conteúdo. Como especificamos o conteúdo dos estados mentais uns dos outros? Simples: usamos frases que pertencem a uma língua pública. Quando Maria afirma que seu cabelereiro é socialista, ela expressa a crença de que seu cabelereiro é socialista. Não se pode afirmar sinceramente que P e logo depois negar que se tem a crença que $\mathrm{P}$ (paradoxo de Moore). Maria tem uma crença que envolve os conceitos CABELEREIRO ${ }^{7}$ e SOCIALISTA. Esses conceitos têm relações com muitos outros que não são plenamente ativados, como o de SISTEMA POLÍTICO, ou de POLÍTICAS SOCIAIS FORTES etc. Além do mais, formamos a maioria de nossos conceitos involuntariamente, sem nos dar conta disso, e estes também entram em pacotes, mas normalmente com um nível de ativação baixo. Como dizia o grande Michael Polanyi $(1958,1966)$ : "Nós sabemos mais do que podemos dizer".

Agora, podemos chegar à nossa conclusão: se aceitarmos o intencionalismo, a tese plausível de que a intencionalidade é a marca do mental, podemos propor essa

\footnotetext{
${ }^{7}$ Sigo aqui a convenção que consiste em usar maiúsculas para denotar conceitos. Assim, na frase "Cavalos são quadrúpedes", a palavra "cavalo" é usada para denotar os cavalos; em "cavalo tem seis letras", estamos falando da própria palavra. É a distinção tradicional entre uso e menção. Mas "CAVALO" denota o conceito de cavalo.
} 
relação entre o intencional e o disposicional: o que é mental é intencional e o que é intencional é a manifestação de disposições. Espero ter avançado na direção de uma solução para ao problema mencionado no início: como um organismo vivo, portanto algo físico, pode ter e manter estados que são acerca de outra coisa? Ao adotar um disposicionalismo generalizado, podemos manter a intencionalidade e seu poder explicativo como marca do mental e de tudo que depende de nossas atividades mentais. O mental, a manifestação de disposições, é assim amarrado ao físico, pois não há disposições sem uma base de realização física.

\section{PRINCIPAIS REFERÊNCIAS}

CARTWRIGHT, N. What makes a capacity a disposition? Center for Philosophy of Natural and Social Sciences.

$<$ Http://personal.lse.ac.uk/cartwright/PapersGeneral/what $\% 20 \mathrm{a} \% 20$ capacity $\% 20 \mathrm{a} \% 20 \mathrm{di}$ sposition.pdf>

CRANE, T. (Org.). Dispositions. A debate. Londres: Routledge, 1996.

DANTO, A. Analytical philosophy of action. Cambridge: C.U.P., 1973.

FISHER, J. C. Dispositions, conditionals and auspicious circumstances. Philosophical Studies, 164(2), 2013, p. 443-464.

GOZZANO, S. The dispositional nature of phenomenal properties. Topoi, 2018. JANSEN, L. On ascribing dispositions. In: Kistler M. \& Gnassounou, B. (Eds.). Dispositions and causal powers. Aldenshot (UK): Ashgate, 2007, p. 161-177. MOLNAR, G. Powers. A study in metaphysics. Oxford: O.U.P., 2003. POLANYI, M. Personal knowledge. Chicago: University of Chicago Press, 1958. . The tacit dimension. Chicago: The University of Chicago Press, 1966.

RECANATI, F. Truth-conditional pragmatics. Oxford: O.U.P., 2010. RUDDER BAKER, L. Naturalism and the first-person perspective. Oxford: O.U.P., 2013.

RYLE, G. The concept of mind. Londres: Hutchinson, 1949.

STALNAKER, R. On what's in the head. Philosophical perspective 3: philosophy of mind and action theory. J. Tomberlin (Ed.), Atascadero CA: Ridgeview Publishing Company, 1989, p. 287-316. 
PROMETHEUS - N. 33 - May - August 2020 - E-ISSN: 2176-5960

Narrow content. In: C. Anthony Anderson \& Joseph Owens

(Eds.). Propositional attitudes: the role of content in logic, language and mind.

Stanford: CSLI, 1990, p. 131-146.

WAISMANN, F. Verifiability. Proceedings of the Aristotelian Society, Supplementary Volume XIX, 1945. 